\title{
Molecular modeling of 4-fluoropyrrolidine-2-carbonitrile and octahydrocyclopenta[b]pyrrole-2-carbonitrile as a dipeptidyl peptidase IV (DPP4) inhibitor
}

\author{
Muhammad Arba $^{1 *}$, Ruslin Ruslin ${ }^{1}$, Nur Illiyyin Akib ${ }^{1}$, Yamin Yamin ${ }^{1}$, Sabarudin Ombe ${ }^{1}$, Jessi Jessi², Muhammad Zakir \\ Muzakkar $^{2}$, Daryono Hadi Tjahjono ${ }^{3}$ \\ ${ }^{1}$ Faculty of Pharmacy, Halu Oleo University, Kendari, Indonesia. \\ ${ }^{2}$ Department of Chemistry, Halu Oleo University, Kendari, Indonesia. \\ ${ }^{3}$ School of Pharmacy, Institut Teknologi Bandung, Bandung, Indonesia.
}

\section{ARTICLE INFO \\ Received on: 01/02/2018 \\ Accepted on: 30/08/2018 \\ Available online: $31 / 10 / 2018$}

\section{Key words:}

Dipeptidyl peptidase, carbonitrile, QSAR,

docking, molecular dynamic simulation, MM-PBSA.

\begin{abstract}
Research on the quantitative structure-activity relationship (QSAR) of the 4-fluoropyrrolidine-2-carbonitrile and octahydrocyclopenta[b]pyrrole-2-carbonitrile as dipeptidyl peptidase IV (DPP4) inhibitor was performed. The molecular descriptors were calculated and the best QSAR model was developed, which satisfied statistical parameters such as correlation coefficient $R=0.912$ and leave-one-out validation coefficients $q^{2}=0.608$. The predictive quality of the model was tested against test set compounds with $R^{2 \text { pred }}$ value of 0.7057 . A novel compound (ND1) was designed and its predicted $\mathrm{IC}_{50}$ was predicted, which was lower compared with that of the parent compound (S24). Molecular docking and molecular dynamics simulation of $40 \mathrm{~ns}$ showed the stability of binding orientation of ND1, the parent compound, and native ligand of DPP4. Prediction of affinity using molecular mechanics/Poisson-Boltzmann/surface area method revealed that the ND1 has a comparable affinity with the parent and natural ligands.
\end{abstract}

\section{INTRODUCTION}

Type 2 diabetes mellitus (T2DM) is a chronic metabolic disease characterized by insulin resistance and insulin deficiency. It affects more than 400 million adults worldwide in 2014, and its global prevalence is estimated to reach 330 and 640 million in 2030 and 2040, respectively (Ahren, 2009; Drucker et al., 2010; Reusch and Manson, 2017).

One of the molecular targets for curing T2DM is dipeptidyl peptidase IV (DPPIV/DPP4). DPP4 is a serine protease which deactivates intestinally derived hormones glucagonlike peptide 1 (GLP-1) and glucose-dependent insulinotropic polypeptide (GIP). GLP-1 is an important incretin hormone that

\section{"Corresponding Author}

Muhammad Arba, Faculty of Pharmacy, Halu Oleo University, Kendari, Indonesia.E-mail:muh.arba@uho.ac.id helps in insulin secretion and suppresses glucagon formation. However, its half-life is very short due to DPP4 catalytic activity. Therefore, inhibiting DPP4 is considered as a novel therapeutic strategy for restoring glucose homeostasis in diabetic patients by leaving more GLP-1 and GIP in the blood circulation (Chahal and Chowdhury, 2007; Demuth et al., 2005; Sneha and Doss, 2016).

Several DPP4 inhibitors have recently been approved by Food and Drug Administration (FDA), such as sitagliptin (Merck), vildagliptin (Novartis), saxagliptin (BMS), alogliptin (Takeda), and linagliptin (Lilly) (Cox et al., 2016). However, their use in the clinical application is not devoid of problems such as severe adverse effects, including hypoglycemia, edema, weight gain, and gastrointestinal distress (Li et al., 2016). Therefore, the need for novel and potent antidiabetic agents with minimum side effects is indispensable. Ji et al. (2014) designed and synthesized novel $\beta$-amino pyrrolo-2carbonitrile derivatives and found that compound 91 showed excellent DPP4 inhibitory activity resulting in decreased blood glucose in vivo. 
To further reveal and develop the structural features of novel derivatives of $\beta$-amino pyrrolo-2-carbonitrile having more potent DPP4 inhibitory activity, 2D-quantitative structure-activity relationship (QSAR) study was carried out to build a linear correlation between physicochemical properties (descriptors) and biological activity of the compounds. The molecular docking was employed to investigate the binding interaction of ligand to the DPP4 enzyme (Abdalsalam, 2017; Arba et al., 2018). The molecular dynamics (MD) simulation coupled with molecular mechanics/Poisson-Boltzmann/surface area (MM-PBSA) free energy prediction was applied to evaluate the ligand-enzyme dynamics during $40 \mathrm{~ns}$ and to predict the binding free energy of the ligand-enzyme complex (Ruslin et al., 2017).

\section{COMPUTATIONAL METHOD}

\section{Data set}

The data set of 24 4-fluoropyrrolidine-2-carbonitrile and octahydrocyclopenta $[b]$ pyrrole-2-carbonitrile derivatives (Table 1) as reported by Ji et al. (2014) were selected. The inhibition activity data $\left(\mathrm{IC}_{50}\right)$ in negative logarithmic scale $\left(\mathrm{pIC}_{50}\right)$ was used, which span from -1.6761 up to 2. Each compound was built and geometrically optimized on semi-empirical Austin Model-1 (AM1) method by using Gaussian 09 software (Frisch et al., 2009). The molecular descriptors were generated for each built structure using molecular operating environment (MOE, 2009.10), which includes total energy (AM1 E), electronic energy (AM1_Eele), dipole moment (AM1_Dipol), formation heat (AM1 HF), highest occupied molecular orbital energy (AM1_HOMO), lowest unoccupied molecular orbital energy (AM1_LUMO), polarity (Apol), hydrophobic surface area (ASA_H), water solubility ( $\log$ S), partition coefficient (Log P), globularity (Glob), van der Waals volume (Vol), and molar refractivity $(\mathrm{Mr})$.

\section{Recognition of outlier}

Outliers are defined as unrelated values in the normal distribution values. In the QSAR model, they must be eliminated to avoid invalid prediction (Zakariazadeh et al., 2015). In the present study, outliers were identified by calculating the value of \$Z-SCORE, in which a compound is considered as an outlier when its $\$ Z$-SCORE value $\geq 2.5$ (Hamerton et al., 2013). The remaining

Table 1. The 4-fluoropyrrolidine-2-carbonitrile and octahydrocyclopenta[ $b]$ pyrrole-2carbonitrile derivatives in the data set.

\begin{tabular}{|c|c|c|c|}
\hline No. & Compound & $\mathbf{R}$ & $\mathrm{IC}_{50}(\mu \mathrm{M})$ \\
\hline 1 & $\mathrm{~A} 1$ & $\mathrm{H}$ & 0.45 \\
\hline 2 & A2 & $2-\mathrm{Cl}$ & 0.22 \\
\hline 3 & A3 & $2-\mathrm{Me}$ & 0.16 \\
\hline 4 & A4 & $3-\mathrm{F}$ & 0.22 \\
\hline 5 & A5 & $4-\mathrm{F}$ & 0.32 \\
\hline 6 & A6 & 4-I & 0.43 \\
\hline 7 & A7 & $4-\mathrm{CF}_{3}$ & 0.64 \\
\hline 8 & A8 & 4-OMe & 0.77 \\
\hline 9 & A9 & 2,4-di-Cl & 0.04 \\
\hline 10 & A10 & 3,4-di-Cl & 0.53 \\
\hline 11 & A11 & 3,5-di-F & 1.58 \\
\hline 12 & A12 & 2,4,5-tri-F & 0.05 \\
\hline 13 & A13 & $\mathrm{H}$ & 1.94 \\
\hline 14 & B14 & $\mathrm{H}$ & 0.44 \\
\hline 15 & B15 & $2-\mathrm{Cl}$ & 0.07 \\
\hline 16 & B16 & 2-Me & 0.36 \\
\hline 17 & B17 & $3-F$ & 0.13 \\
\hline 18 & B18 & $4-\mathrm{F}$ & 0.27 \\
\hline 19 & B19 & 4-I & 8.80 \\
\hline 20 & B20 & $4-\mathrm{CF}_{3}$ & 1.98 \\
\hline 21 & B21 & 2,4-di-Cl & 0.07 \\
\hline 22 & B22 & 3,4-di-Cl & 47.44 \\
\hline 23 & B23 & 3,5-di-F & 9.65 \\
\hline 24 & B24 & 2,4,5-tri-F & 0.01 \\
\hline
\end{tabular}


compounds were then randomly grouped into a training set (18 compounds) and a test set (five compounds) considering their structural diversity and biological activities.

\section{QSAR model}

The calculation of the QSAR model was achieved by using the multiple linear regression approach using the SPSS for Windows version 19 to establish the linear relationship between a set of descriptors and biological activity. The best QSAR model was identified using several statistical parameters, such as squared correlation coefficient $\left(R^{2}\right)$, Fischer's value for statistical significance $(F)$, adjusted squared correlation coefficient $\left(R_{\text {adj }}^{2}\right)$, and standard error of estimation (Arba et al., 2018; Dearden et al., 2009). Besides, the QSAR equation was also validated by internal validation of leave-one-out (LOO) cross-validation coefficient $\left(q^{2}\right)$ (Golbraikh and Tropsha, 2002). The LOO cross-validation works by eliminating each compound in the training set and predicting the biological activity using the model of remaining compounds. The calculation of LOO cross-validation coefficient $\left(q^{2}\right)$ was described elsewhere (Arba et al., 2018), in which a value of $q^{2}$ which is higher than 0.5 is necessary to assure the predictability of the built QSAR equation (Golbraikh et al., 2003; Tropsha et al., 2003). Furthermore, in addition to internal cross-validation, the reliability of the built model was also evaluated externally, in which the model was used to predict the biological activity of the test set compounds (Tropsha et al., 2003). In that scheme, the validity of the model was evaluated using the external cross-validation coefficient $\left(R^{2 \text { pred }}\right)$, in which the $R^{2 \text { pred }}$ value higher than 0.6 is necessary to assure the validity of the built model.

\section{Design for new molecule and molecular docking}

Based on built QSAR equation, a new compound (ND1) was proposed and its predicted biological activity $\left(\mathrm{IC}_{50 \text { pred }}\right)$ was calculated. The biological activity of the ND1 was then compared with that of the parent compound (S24), which has the lowest observed $\mathrm{IC}_{50}\left(\mathrm{IC}_{50}=0.01 \mu \mathrm{M}\right)$. Furthermore, molecular docking of ND1 and S24 to DPP4 protein was performed to reveal the interaction mechanism of those compounds in the binding site of DPP4 by using AutoDock 4.2 (Morris et al., 1998). The crystallographic structure of DPP4 from the Protein Data Bank (PDB) with PDB code 2AJL and resolution $2.5 \AA$ was selected (Qiao et al., 2006). The grid box was located following the catalytic cavity with the dimension of 50 in each $x y z$ direction. The default values were used for other docking parameters (Arba et al., 2017a).

\section{MD simulation and prediction of binding free energy}

MD simulation was performed on each S24, ND1, and native ligand 1-[2-(s)-amino-3-biphenyl-4-yl-propionyl]pyrrolidine-2-(s)-carbonitrile (JNH), each complexed with DPP4 using Amber 16 package (Case et al., 2015; Salomon-Ferrer et al., 2013). In the present study, the ff14SB force field was used to describe the protein, while GAFF (General Amber force field) and AM1-BCC were used to describe ligand (Jakalian et al., 2002; Maier et al., 2015; Wang et al., 2004). Each system was neutralized by the addition of $\mathrm{Na}^{+}$ions and then solvated using the TIP3P box water model with a distance of $1 \mathrm{~nm}$ around the complex. The minimization, heating, and equilibration were performed with the aid of Sander module following our previous procedure (Arba et al., 2018). The production step was performed using GPU version of the PMEMD engine of Amber 16 package for $40 \mathrm{~ns}$ in NPT ensemble without restraint using Langevin thermostat at $1.0 \mathrm{ps}^{-1}$ random collision frequency to maintain the system in $300 \mathrm{~K}$ thermal bath. The SHAKE algorithm was used to restrain bonds involving hydrogen atoms (Ryckaert et al., 1977). The long-range electrostatic interactions were treated with the particle-mesh Ewald method with an integration step of 2 fs (Darden et al., 1993) by applying periodic boundary conditions with a cutoff distance of $9.0 \AA$. The CPPTRAJ module (Roe and Cheatham, 2013) was used to performed analysis, including root mean square deviations (RMSD) and root mean square fluctuation (RMSF), while visual molecular dynamics was used for visualization (Humphrey et al., 1996).

The prediction of free energy of binding was achieved by performing MM/PBSA following our previous protocol (Arba et al., 2017b; 2018; Kollman et al., 2000; Miller et al. 2012).

\section{RESULTS AND DISCUSSION}

The QSAR study was performed to reveal structureactivity relationship of $\beta$-amino pyrrolo-2-carbonitrile as a DPP4 inhibitor. The outlier of the data set was first determined using \$Z-SCORE. Calculation of the values of \$Z-SCORE identified S22 and S24 as outliers with \$Z-SCORE values of 3.10848 and 2.7395 , respectively. Theoretically, both compounds should be removed from the data set to improve the QSAR model. However, in the present study, only S22 was removed, while compound S24 was kept in the data set since it is the most active compound experimentally. Furthermore, 23 compounds of the data set were divided randomly into a training set (18 compounds), which was used to build QSAR model, and a test set (five compounds), which was used to test the predictive ability of the built model (Table 2 ). The test set was selected by considering the distribution of biological activity in the whole data set.

Furthermore, multiple linear regression analysis was applied to build the QSAR models using 18 compounds of a training set. The resulted QSAR model contains five molecular descriptors, i.e., dipole moment (AM1 dipol), HOMO energy (AM1_HOMO), LUMO energy (AM1_LUMO), partition coefficient $(\log \mathrm{P})$, and molar refractivity $(\mathrm{Mr})$. The following equation shows the best QSAR model:

$$
\begin{gathered}
\mathrm{pIC}_{50}=75.842-0.579(\mathrm{AM} 1 \text { dipole })+5.359\left(\mathrm{AM} 1_{-}\right. \\
\text {HOMO })-5.297\left(\mathrm{AM} 1 \_L U M O\right)+2.278(\mathrm{Log} \mathrm{P})-3.070(\mathrm{Mr})
\end{gathered}
$$

The above equation fulfills statistical criteria such as the correlation coefficient $(R)$, determination coefficient $\left(R^{2}\right)$, and Fischer's value $(F)$ of $0.912,0.831$, and 11.820 , respectively. The quality of the model was also indicated by the low standard error (SE) of 0.3290 . The value of LOO cross-validation coefficient $q^{2}$ of 0.608 indicated that the model was valid. Table 3 shows molecular descriptors and statistical parameters of the built QSAR model.

The QSAR model indicates that the biological activity would increase with more lipophilic groups as indicated by the positive sign of coefficient of Log P. On the other hand, less steric groups were favorable for increasing the biological activity as indicated by the negative sign of the coefficient of Mr. Meanwhile, 
Table 2. The value of \$Z-SCORE and data set division. Compounds assigned as * and ** are outlier and test set, respectively.

\begin{tabular}{|c|c|c|c|c|}
\hline No. & Compound & Code & $\mathrm{pIC}_{50}$ & \$Z-SCORE \\
\hline 1 & A1 & S1 & 0.34679 & 0.02637 \\
\hline 2 & A2 & S2 & 0.65758 & 0.34277 \\
\hline 3 & $\mathrm{~A} 3$ & S3 & 0.79588 & 0.63559 \\
\hline 4 & A4 & S4 & 0.65758 & 0.28256 \\
\hline 5 & A5 & $\mathrm{S} 5^{* *}$ & 0.49485 & 0.05558 \\
\hline 6 & A6 & S6 & 0.36653 & 0.06973 \\
\hline 7 & A7 & S7 & 0.19382 & 0.6272 \\
\hline 8 & A8 & S8 & 0.11351 & 0.3386 \\
\hline 9 & A9 & S9 & 1.39794 & 1.288 \\
\hline 10 & $\mathrm{~A} 10$ & $\mathrm{~S} 10^{* *}$ & 0.27572 & 0.25733 \\
\hline 11 & A11 & S11 & -0.1987 & 1.0489 \\
\hline 12 & $\mathrm{~A} 12$ & $\mathrm{~S} 12^{* *}$ & 1.30103 & 1.14483 \\
\hline 13 & A13 & S13** & -0.2878 & 0.95978 \\
\hline 14 & B14 & S14 & 0.35655 & 0.24665 \\
\hline 15 & B15 & S15 & 1.1549 & 1.34364 \\
\hline 16 & B16 & S16 & 0.4437 & 0.45808 \\
\hline 17 & B17 & S17 & 0.88606 & 0.82957 \\
\hline 18 & B18 & S18 & 0.56864 & 0.3929 \\
\hline 19 & B19 & S19 & -0.9445 & 1.69089 \\
\hline 20 & B20 & S20 & -0.2967 & 1.18939 \\
\hline 21 & B21 & S21 & 1.1549 & 1.25829 \\
\hline 22 & B22 & S22* & -1.6761 & 3.10848 \\
\hline 23 & B23 & S23** & -0.9845 & 1.90469 \\
\hline 24 & B24 & $\mathrm{S} 24$ & 2 & 2.7395 \\
\hline
\end{tabular}

Table 3. Statistical parameters of best QSAR equation for $\beta$-amino pyrrole-2carbonitrile derivatives.

\begin{tabular}{lccccc}
\hline Descriptors & $\boldsymbol{q}^{2}$ & $\boldsymbol{R}$ & $\boldsymbol{R}^{\mathbf{2}}$ & $\begin{array}{c}\text { Adjusted } \\
\boldsymbol{R}^{\mathbf{2}}\end{array}$ & SE \\
\hline $\begin{array}{l}\text { AM1_Dipole, AM1_HOMO, } \\
\text { AM1_LUMO, Log } \mathrm{P}(\mathrm{o} / \mathrm{w}), \mathrm{Mr}\end{array}$ & 0.608 & 0.912 & 0.831 & 0.761 & 0.329 \\
\hline
\end{tabular}

the negative contribution of AM1_Dipole and AMI_LUMO to biological activity was noted as implied by the negative sign of their coefficients. Compared to the other four descriptors, AM1_HOMO is the most influencing descriptor as indicated by the highest coefficient value.Furthermore, Tropsha et al. (2003) indicated that a QSAR model must be validated externally by test set compounds, in which $R^{2 \text { pred }}$ value of training and test set must be higher than 0.6. Our QSAR analysis revealed the value of $R^{2 \text { pred }}=0.7057$, indicating the validity of the built model. The relationship between observed and predicted $\mathrm{pIC}_{50}$ both training and test set is depicted in Figure 1.

\section{The design of new compound and molecular docking}

With the aim of finding the new potent $\beta$-amino pyrrolo2-carbonitrile derivative, a ND1 was designed by using the built QSAR model. Table 4 shows the structures of S24 and ND1. The results of predicting biological activity revealed that the predicted

Table 4. The structures of S24 and ND1.

Compound




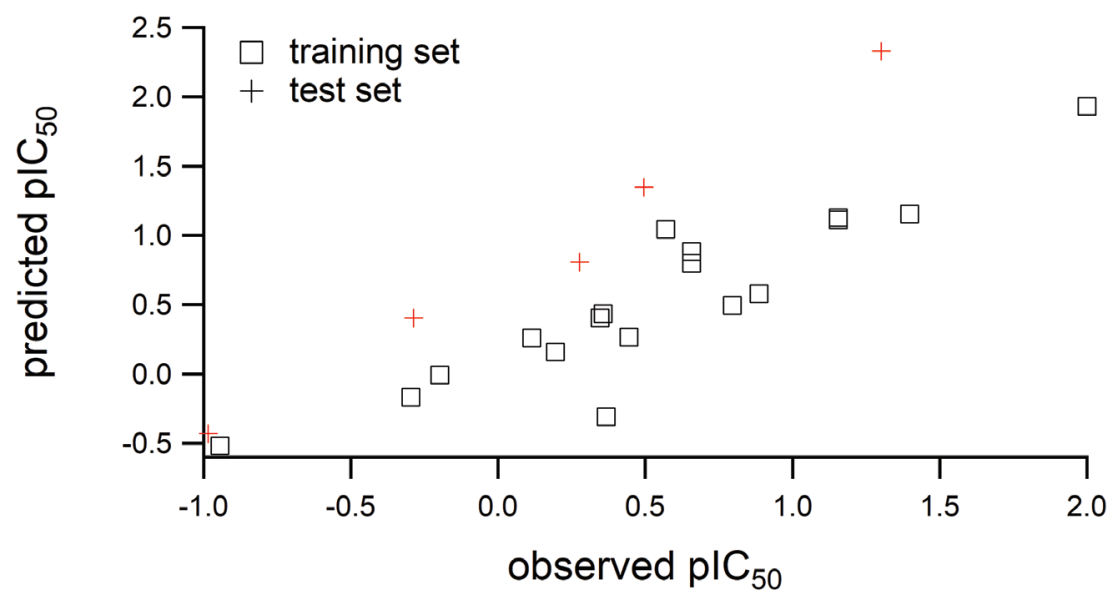

Figure 1. The plot for observed $\mathrm{pIC}_{50}(\mathrm{X})$ and predicted $\mathrm{pIC}_{50}(\mathrm{Y})$ of $\beta$-amino pyrrole-2-carbonitrile derivatives.

$\mathrm{IC}_{50}$ of ND1 was lower $\left(\mathrm{IC}_{50 \mathrm{pred}}=0.000340859 \mu \mathrm{M}\right)$ than that of $\mathrm{S} 24\left(\mathrm{IC}_{50 \mathrm{pred}}=0.015279802 \mu \mathrm{M}\right)$.

Next, molecular docking of S24 and ND1 on DPP4 was performed to examine the preferred orientation of ligand to the protein. Molecular docking was commenced by redocking native ligand $(\mathrm{JNH})$ on the protein to examine the reliability of docking protocol. In the docked conformation, JNH established hydrogen bonds (H-bonds) with Glu206 and Tyr547 as well as hydrophobic interactions with Phe357 and His740. The H-bond with Glu205 and hydrophobic interactions with Phe357 and His740 was also observed in the X-ray crystallographic conformation. Figure 2 shows the docked and $\mathrm{X}$-ray crystallographic conformations of JNH with the RMSD of $1.21 \AA$, indicating that the docking protocol was valid (Jones et al., 1997; Morris et al., 1998).

The molecular docking poses showed that both S24 and ND1 were able to interact with active site residues of DPP4. Several H-bonds were formed with Glu205, Glu206, and Arg669 in the binding of ND1. Interestingly, fluor atom interacted through H-bonds with Arg125, Tyr631, Asn710, and His740. Moreover, pi-pi stacking interactions between ND1 with Tyr662 and Tyr666 were also established. On the other hand, binding of S24 was

a.
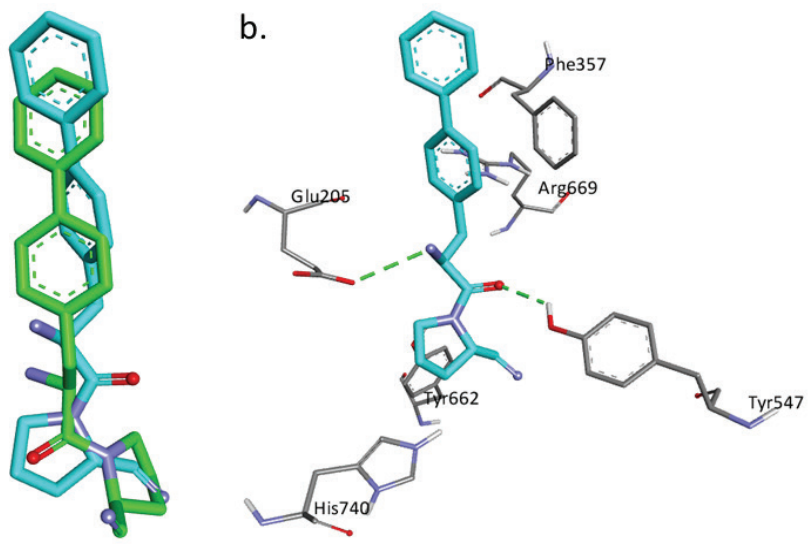

Figure 2. The docked (green) and experimental (blue) poses of JNH and the interaction of JNH in the binding site of DPP4. maintained by H-bonds with Glu205, Glu206, and Asn710, as well as by pi-pi stacking interactions with Tyr662 and Tyr666. It is noted that H-bonds with Glu205 and Asn710 were also detected in X-ray crystallographic pose. The hydrophobic interaction including with Phe357 was also observed. It was clear from the docked poses that ND1 established more interactions that that of S24. Figure 3 depicts the binding mode of S24 and ND1 in the binding cavity of DPP4. a.

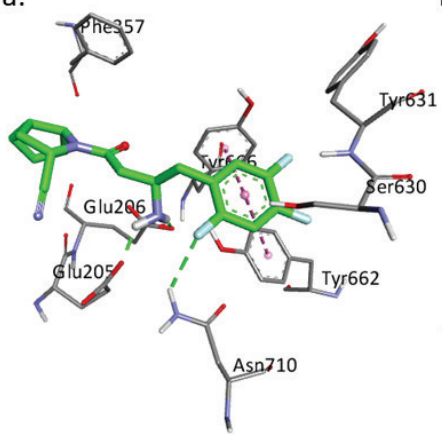

b.

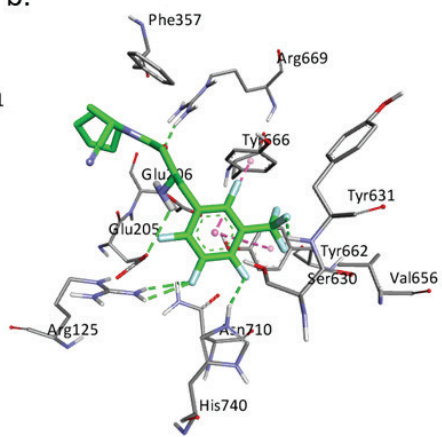

Figure 3. The docked conformation of (a) S24 and (b) ND1. The hydrogen bond and pi-pi stacking interactions are represented in green and pink colored dashed lines, respectively.

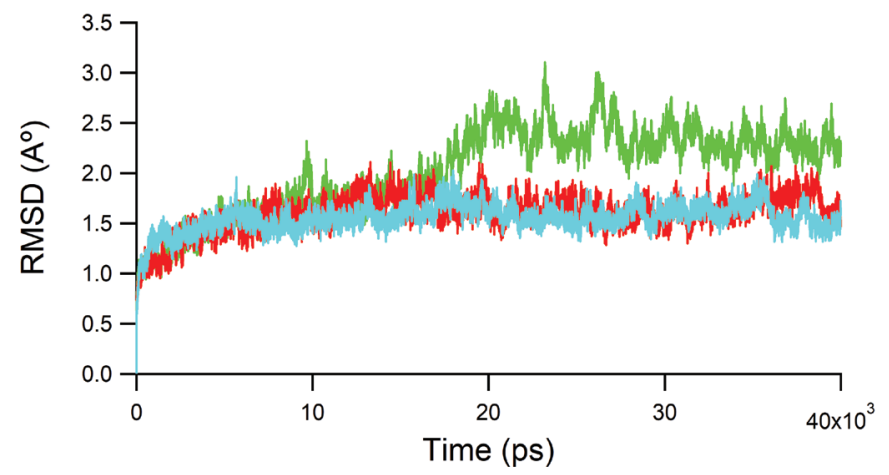

Figure 4. The RMSD plot of each JNH (red), S24 (green), and ND1 (blue) complexed to DPP4. 


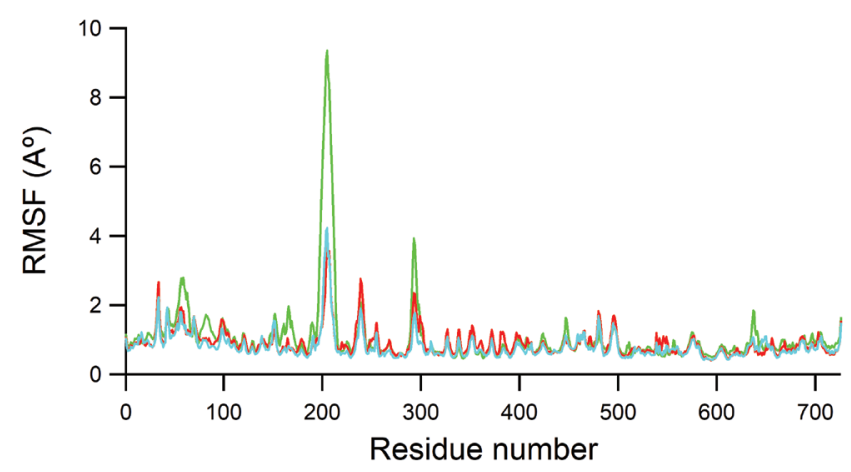

Figure 5. The RMSF plot vs. residue number of JNH (red), S24 (green), and N1 (blue), each complexed with DPP4.

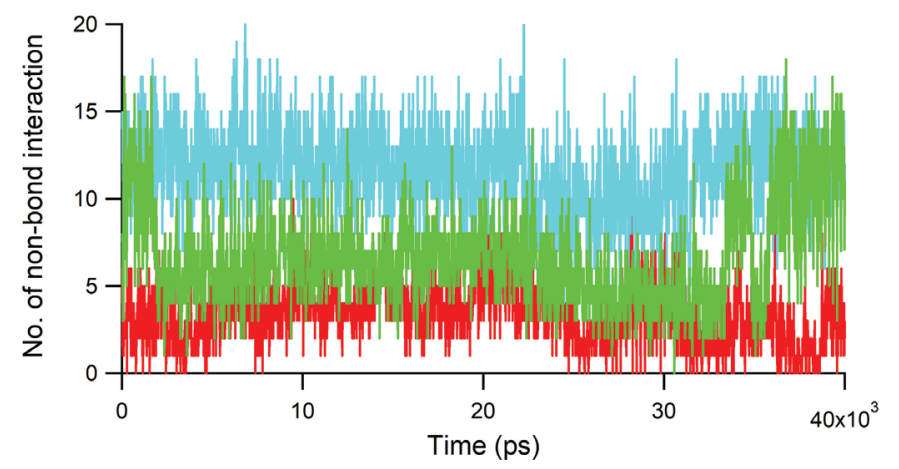

Figure 6. The number of non-bond interactions vs. time: JNH (red colored line), S24 (green colored line), and ND1 (blue colored line).

Table 5. The calculated free energy of binding ( $\mathrm{kcal} / \mathrm{mol})$ of each S24, ND1, and native ligand (JNH).

\begin{tabular}{ccccccc}
\hline Comp & $\Delta \boldsymbol{E}_{\mathrm{ELE}}$ & $\Delta \boldsymbol{E}_{\mathrm{VDW}}$ & $\Delta \boldsymbol{E}_{\mathrm{PBCAL}}$ & $\Delta \boldsymbol{E}_{\mathrm{PBSUR}}$ & $\Delta \boldsymbol{E}_{\mathrm{PBELE}}$ & $\Delta \boldsymbol{G}_{\mathrm{PBTOT}}$ \\
\hline $\mathrm{JNH}$ & -2.17 & -35.03 & 21.84 & -4.59 & 19.67 & -19.96 \\
$\mathrm{~S} 24$ & -20.44 & -38.39 & 37.48 & -5.38 & -26.73 & 17.04 \\
$\mathrm{ND} 1$ & -17.92 & -41.46 & 41.04 & -3.80 & 23.12 & -22.14 \\
\hline
\end{tabular}

\section{Molecular dynamics simulation}

The docked conformation of each S24, ND1, and JNH was monitored for their conformational stability through MD simulation of $40 \mathrm{~ns}$. The conformation stability was checked by using the values of RMSD. Figure 4 shows the RMSD plot of heavy atoms of DPP4 with respect to simulation time for each complex. As Figure 4 shows, JNH and ND1 reached stability after about $7 \mathrm{~ns}$. On the other hand, the complex of the parent compound (S24) shows slight fluctuation after 20 ns. However, considering its fluctuation, which is about $3 \AA$, it can be inferred that the complex was sufficiently stable. The dynamics simulation was also used to monitor the fluctuation of amino acid residues due to ligand binding during 40 ns. Figure 5 shows the RMSF of protein versus residue number. All complexes show a similar pattern of RMSF, which indicates the similar binding mode. The highest fluctuation was recorded in the amino acid residue Ser205 (Ser245) which was due to beta helix end.

\section{Binding energy prediction by $M M / P B S A$}

Table 5 shows the calculated binding free energy of each S24, ND1, and JNH bound to the DPP4. The MM-PBSA prediction showed that the binding free energy is slightly lower in parent compound (S24) $\left(\Delta G_{\text {Рвтот }}=-26.73 \mathrm{kcal} / \mathrm{mol}\right)$ and ND1 $\left(\Delta G_{\text {Рвтот }}=-22.14 \mathrm{kcal} / \mathrm{mol}\right)$ compared to JNH $\left(\Delta G_{\text {Рвтот }}\right.$ $=-19.96 \mathrm{kcal} / \mathrm{mol})$. The better affinities of S24 and ND1 were also reflected by the total number of nonbond interactions during simulation period of 40 ns (Fig. 6), in which both S24 and ND1 have more number of interactions than that of JNH. The S24DPP4 complex also displayed a slightly lower electrostatic energy $\left(\Delta E_{\mathrm{ELE}}=-20.44 \mathrm{kcal} / \mathrm{mol}\right)$ compared to the ND1 and JNH complexes $\left(\Delta E_{\mathrm{ELE}}=-17.92\right.$ and $-2.17 \mathrm{kcal} / \mathrm{mol}$, respectively). However, van der Waals energy was slightly lower in ND1 $\left(\Delta E_{\mathrm{VDW}}=-41.46 \mathrm{kcal} / \mathrm{mol}\right)$ compared to $\mathrm{S} 24$ and $\mathrm{JNH}\left(\Delta E_{\mathrm{VDW}}\right.$ $=-38.39$ and $-35.03 \mathrm{kcal} / \mathrm{mol}$, respectively). Meanwhile, the contribution of the nonpolar energy of desolvation $\left(\Delta E_{\mathrm{PBSUR}}\right)$ was almost the same for all complexes. The contribution of the polar energy of desolvation is higher in ND1 $\left(\Delta E_{\mathrm{PBCAL}}=41.04 \mathrm{kcal} / \mathrm{mol}\right)$ compared to $\mathrm{S} 24$ and JNH $\left(\Delta E_{\mathrm{PBCAL}}=37.48\right.$ and $21.84 \mathrm{kcal} / \mathrm{mol}$, respectively). In the meantime, the total electrostatic contribution was lower in S24 $\left(\Delta E_{\mathrm{PBELE}}=17.04 \mathrm{kcal} / \mathrm{mol}\right)$ compared to the $\mathrm{ND} 1$ and $\mathrm{JNH}\left(\Delta E_{\mathrm{PBELE}}=23.12\right.$ and $19.67 \mathrm{kcal} / \mathrm{mol}$, respectively), resulting in the lowest total binding free energy in S24 compared to those in ND1 and JNH.

\section{CONCLUSION}

In the present study, a QSAR model of five descriptors which correlate structure and inhibitory activity of DPP4 of $\beta$-amino pyrrolo-2-carbonitrile derivatives was developed. It was then used to design ND1 which has lower predicted $\mathrm{IC}_{50}$ than the parent compound. The ND1 interacted with the active site of the DPP4 protein and its complex with DPP4 protein was stabilized during $40 \mathrm{~ns}$ MD simulation. This study identifies ND1, with binding affinity amenable to the further study of the discovery of DPP4 inhibitor.

\section{REFERENCES}

Abdalsalam AAA. In-silico virtual screening and ADMET study to find novel neuraminidase N1 inhibitors extended to the 150-cavity. J App Pharm Sci, 2017; 7(05):024-33.

Ahren B. Islet $\mathrm{G}$ protein-coupled receptors as potential targets for treatment of type 2 diabetes. Nat Rev Drug Disc, 2009; 8:369-85.

Arba M, Ihsan S, Ramadhan LOAN, Tjahjono DH. In silico study of porphyrin-anthraquinone hybrids as CDK2 inhibitor. Comput Biol Chem, 2017a; 67:9-14.

Arba M, Ruslin, Ihsan S, Wahyudi ST, Tjahjono DH. Molecular modeling of cationic porphyrin-anthraquinone hybrids as DNA topoisomerase II $\beta$ inhibitors, Comput Biol Chem, 2017b; 71:129-35.

Arba M, Ruslin, Kalsum WU, Alroem A, Muzakkar MZ, Usman I, et al. QSAR, molecular docking and dynamics studies of quinazoline derivatives as inhibitor of phosphatidylinositol 3-kinase. J App Pharm Sci, 2018; 8(05):001-9.

Case DA, Babin V, Berryman JT, Betz RM, Cai Q, Cerutti DS, Cheatham TE III, et al. AMBER 16. University of California, San Francisco, CA, 2015 
Chahal H, Chowdhury TA. Gliptins: a new class of oral hypoglycaemic agent. Q J Med, 2007; 100:671-7.

Cox JM, Chu HD, Kuethe JT, Gao Y-T, Scapin G, Eiermann G, et al. The discovery of novel 5,6,5- and 5,5,6-tricyclic pyrrolidines as potent and selective DPP-4 inhibitors. Bioorg Med Chem Lett, 2016; 26:2622-6.

Darden T, York D, Pedersen L. Particle mesh Ewald: An $\mathrm{N} \cdot \log (\mathrm{N})$ method for Ewald sums in large systems. J Chem Phys, 1993; 98:10089-92.

Dearden JC, Cronin MTD, Kaiser KLE. How not to develop a quantitative structure-activity or structure-property relationship (QSAR/ QSPR). SAR QSAR Environ Res, 2009; 20:241-66.

Demuth HU, McIntosh CHS, Pederson RA. Type 2 diabetesTherapy with dipeptidyl peptidase IV inhibitors. Biochim Biophys Acta, $2005 ; 1751: 33-44$

Drucker DJ, Sherman SI, Gorelick FS, Bergenstal RM, Sherwin RS, Buse JB. Incretin-based therapies for the treatment of type 2 diabetes: evaluation of the risks and benefits. Diab Care, 2010; 33:428-33.

Frisch MJ, Trucks GW, Schlegel HB, Scuseria GE, Robb MA, Cheeseman JR, et al. Gaussian 09, Revision B.01., Gaussian, Inc., Wallingford, CT, 2009.

Golbraikh A, Shen M, Xiao Z, Xiao YD, Lee KH, Tropsha A. Rational selection of training and test sets for the development of validated QSAR models. J Comput Aided Mol Des, 2003; 17:241-53.

Golbraikh A, Tropsha A. Beware of q2! J Mol Graph Model, 2002; 20(4):269-76.

Hamerton I, Howlin BJ, Mhlanga P, Hassan WAW. Using QSPR techniques to predict char yield arisin Frisch $\mathrm{g}$ from the thermal degradation of polybenzoxazines. Pol Deg Stab, 2013; 98:446-52.

Humphrey W, Dalke A, Schulten K. VMD-visual molecular dynamics. J Mol Graph, 1996; 14:33-8.

Jakalian A, Jack DB, Bayly CI. Fast, efficient generation of high-quality atomic charges. AM1-BCC model: II. Parameterization and validation. J Comput Chem, 2002; 23:1623-41.

Ji X, Xia C, Wang J, Su M, Zhang L, Dong T, et al. Design, synthesis and biological evaluation of 4-fluoropyrrolidine-2-carbonitrile and octahydrocyclopenta[$[b]$ pyrrole-2-carbonitrile derivatives as dipeptidyl peptidase IV inhibitors. Eur J Med Chem, 2014; 86:242-56.

Jones G, Willett P, Glen RC, Leach AR, Taylor R. Development and validation of a genetic algorithm for flexible docking. J Mol Biol, 1997; 267:727-48.

Kollman PA, Massova I, Reyes C, Kuhn B, Huo S, Chong L, et al. Calculating structures and free energies of complex molecules: combining molecular mechanics and continuum models accounts. Chem Res, 2000; 33:889-97.

Li S, Xu H, Cui S, Wu F, Zhang Y, Su M, et al. Discovery and rational design of natural-product-derived 2Phenyl-3,4-ihydro2Hbenzo[f ]chromen-3-amine analogs as novel and potent dipeptidyl peptidase 4 (DPP-4) inhibitors for the treatment of type 2 diabetes. J Med Chem, 2016; 59:6772-90.

Maier JA, Martinez C, Kasavajhala K, Wickstrom L, Hauser KE, Simmerling C. ff14SB: improving the accuracy of protein side chain and backbone parameters from ff99SB. J Chem Theory Comput, 2015; 11(8):3696-713.

Miller BR, McGee TD, Swails JM, Homoeyer N, Gohlke H, Roitberg AE. MMPBSA.py: an efficient program for end-state free energy calculations. J Chem Theory Comput, 2012; 8:3314-21.

Molecular Operating Environment (MOE). Version 2009.10. Chemical Computing Group Inc., Montreal, Quebec, Canada, 2009.

Morris GM, Goodsell DS, Halliday RS, Huey R, Hart WE, Belew RK, Olson AJ. Automated docking using a Lamarckian genetic algorithm and an empirical binding free energy function. J Comput Chem, 1998; 19:1639-62.

Qiao L, Baumann CA, Crysler CS, Ninan NS, Abad MC, Spurlino JC, et al. Discovery, SAR, and X-ray structure of novel biarylbased dipeptidyl peptidase IV inhibitors. Bioorg Med Chem Lett, 2006; 16:123-8.

Reusch JEB, Manson JE. Management of type 2 diabetes in 2017: getting to goal. JAMA, 2017; 317(10):1015-6.

Roe DR, Cheatham TE III. PTRAJ and CPPTRAJ: Software for processing and analysis of molecular dynamics trajectory data. J Chem Theo Comput, 2013; 9:3084-95.

Ruslin, Nirwana, Arba M, Mukhsar, Tjahjono DH. QSAR, molecular docking and dynamics studies of pyrrolo[2,3-b]pyridine derivatives as Bruton's tyrosine kinase inhibitors. J App Pharm Sci, 2017; 7(12):001-7.

Ryckaert J-P, Ciccotti G, Berendsen HJC. Numerical integration of the cartesian equations of motion of a system with constraints: molecular dynamics of n-alkanes. J Comput Phys, 1977; 23:327-41.

Sneha P, Doss CGP. Review Gliptins in managing diabetesReviewing computational strategy. Life Sci, 2016; 166:108-20.

Salomon-Ferrer R, Goetz AW, Poole D, Grand SL, Walker RC Routine microsecond molecular dynamics simulations with AMBER-Part II: Particle Mesh Ewald. J Chem Theory Comput, 2013; 9(9):3878-88.

Tropsha A, Gramatica P, Gombar VK. The importance of being earnest: validation is the absolute essential for successful application and interpretation of QSPR models. QSAR Comb Sci, 2003; 22:69-77.

Wang J, Wolf RM, Caldwell JW, Kollman PA, Case DA Development and testing of a general amber force field. J Comput Chem, 2004; 25:1157-74.

Zakariazadeh M, Barzegar A, Soltani S, Aryapour H. Developing 2D-QSAR models for naphthyridine derivatives against HIV-1 integrase activity. Med Chem Res, 2015; 24:2485-504.

How to cite this article:

Arba M, Ruslin R, Akib N, Yamin Y, Ombe S, Jessi J, et al. Molecular modeling of 4-fluoropyrrolidine-2-carbonitrile and octahydrocyclopenta[ $b]$ pyrrole-2-carbonitrile as a Dipeptidyl Peptidase IV (DPP4) Inhibitor. J App Pharm Sci, 2018; 8(10): 001-007. 